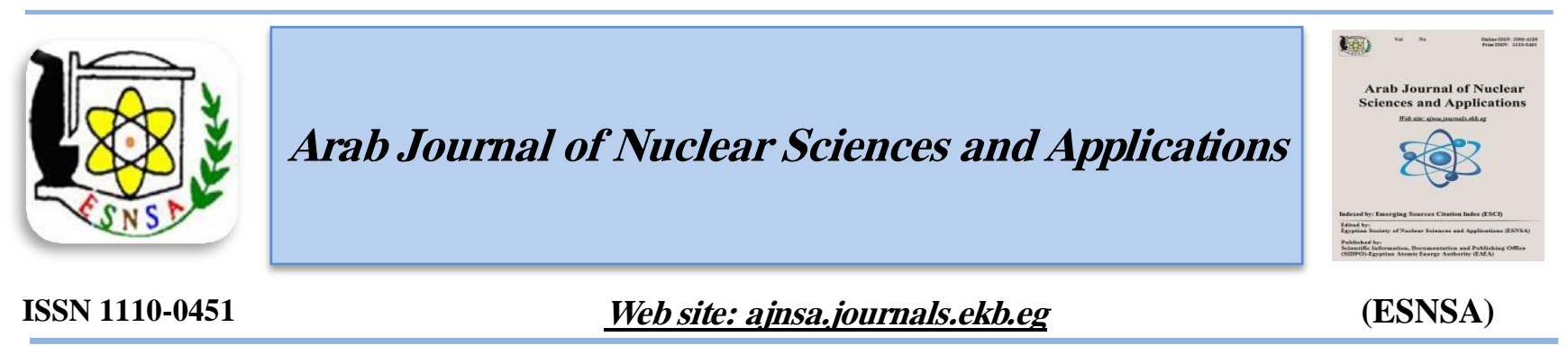

\title{
The Effect of Boron and Titanium Addition on the Behavior of Steel Alloys of Base Composition AISI304Mo as a Nuclear Radiation Shielding Material
}

\author{
Shaimaa Hafez ${ }^{(1)^{*}}$, S. U. El-Kameesy ${ }^{(1)}$, M. M. Eissa ${ }^{(2)}$, R. M. Elshazly ${ }^{(3)}$, \\ M. K. El Fawkhry ${ }^{(2)}$, Aly Saeed ${ }^{(4)}$ \\ ${ }^{I}$ Physics Department, Faculty of Science, Ain Shams University, Cairo, Egypt \\ ${ }^{2}$ Steel Technology Department, Central Metallurgical Research and Development Institute (CMRDI), Helwan, Egypt \\ ${ }^{3}$ Physics Department, Faculty of Science, Al-Azhar University, Cairo, Egypt \\ ${ }^{4}$ Nuclear Power Stations Department, Faculty of Engineering, Egyptian Russian University, Cairo, Egypt
}

Received $10^{\text {th }}$ Oct. 2018 Borated stainless-steel alloys are candidate neutron absorber materials for criticality control in disposal Accepted $17^{\mathrm{h}}$ Apr. 2019 containers or dry storage canisters. Type 304Mo borated stainless steels are similar to conventional Type 304Mo stainless steels except that they contain a boron addition, which imparts a much higher thermal neutron absorption cross section than other austenitic stainless steels. Three grades of steel alloys with base composition of AISI304Mo but having either Ti or B or Ti and B (SS304MoTi, SS304MoB and SS304MoTiB) were modified and produced using $30 \mathrm{~kg}$ pilot plant medium frequency induction furnace under similar conditions. The macroscopic-cross sections for neutrons of energy higher than $10 \mathrm{keV}$, slow, and total slow neutrons were measured using ${ }^{241} \mathrm{Am}-\mathrm{Be}$ neutron source for the produced samples. The developed boron and boron-titanium stainless steel alloys were found to have higher cross sections for neutrons higher than $10 \mathrm{keV}$, slow, and total slow neutrons than SS304Mo. Moreover, the associated neutron half value layer (HVL) was calculated for each sample. Additionally, gamma ray shielding properties were measured for several gamma ray energies that emitted from ${ }^{232} \mathrm{Th}$ radioactive source. Among the investigated steels, the lowest corrosion rate was found in the modified steel containing boron. Samples of the properly treated steels were subjected to microstructure observation, hardness, tensile and impact testing. The microstructure observation revealed an austenitic phase in all investigated steel alloys and a very large number of twins in the optical micrographs of the investigated samples. The strengthening effect of $\mathrm{B}$ or $\mathrm{Ti}$ and $\mathrm{B}$ is to great extent the reason of the solution hardening and precipitation strengthening effects of these elements as these elements are strong carbide or nitride formers. The higher B content increases the formation speed of intermetallic compounds and lowers the ductility.

Keywords: Boron, Titanium and boron-titanium stainless steel, Attenuation, Corrosion rate, Structural and mechanical properties

\section{Introduction}

The hope to face the demands of having sufficient energy to improve world's economy and the standards of personal and international income, civilized nations have to consider nuclear energy. According to the World Nuclear Association, as of October 2011 there were 432 commercial nuclear reactors operating worldwide with an additional 63 reactors under construction. Another 152 reactors were planned and another 350 nuclear reactors proposed for construction. These 502 additional nuclear reactors were expected to be operational by 2030[10].

Corresponding author: shaimaahafez7@outlook.com

DOI: 10.21608/ajnsa.2019.5818.1131

(C) Scientific Information, Documentation and Publishing Office (SIDPO)-EAEA 
According to the nuclear reactor design, removal of a one third of the nuclear fuel rods in the reactor was performed approximately every 12 to 24 months. These spent nuclear fuel rods were normally placed into a temporary on-site storage facility where the spent fuel rods were cooled for at least a year and typically several years, then transfer to another dry storage [1].

Many nuclear power plants have used specially designed storage racks and containers or casks made from boron-containing stainless steel as a shielding material to control the flow of thermal neutrons in the spent nuclear fuel bundles, or rods. These racks or casks were designed to hold 40 to 60 rods [10].

Borated stainless steels have a stable microstructure and mechanical properties under exposure to long-term thermal neutron irradiation. The boron contained in borated stainless steels is usually natural boron, which consists of two isotopes, nominally $18.4 \mathrm{wt} \%{ }^{10} \mathrm{~B}$, a boron isotope that absorbs thermal neutrons, and nominally $81.6 \mathrm{wt} \%{ }^{11} \mathrm{~B}$, a boron isotope that nearly does not absorb neutrons[1].

Because of the higher ability for neutron absorption, borated stainless steel racks have replaced the austenitic stainless steel (AISI304) racks used in nuclear domains [2]. Borated stainless steels racks were able to store 1.4 to 3 times more neutrons compared with austenitic stainless-steels[3].

During early stage, fabrication of structures with borated stainless steels was done using interesting process, but this process was slow and could not be automated, contributing to higher fabrication cost. Several researches have been made to use an automated process for the joining of borated stainless steels [4].

It was investigated that the borated stainless steels have a behavior similar to binary irregular eutectic alloys such as Fe-C and Al-Si [4]. Furthermore the weldability of borated stainless steels AISI304 type concluded that they are not substantially different from that of conventional austenitic stainless steels [5]. Also, the hot cracking is not probably to occur if boron ratio of higher than $0.6 \%$ are made to AISI 304 stainless steel.

Accordingly, the aim of the present work is to investigate the attenuation, structural, and mechanical properties of boron, titanium and boron - titanium stainless steels in order to assess their beneficial uses in the nuclear reactor domains

\section{Materials and Methods \\ Sample preparation}

To produce titanium, boron and titanium-boron austenitic stainless steels with base composition of SS304Mo a series of experiments were performed to locally produce titanium and/or titanium borated austenitic stainless steel taking into consideration SS304Mo as a base composition. Many attempts were designed to calculate the material balance. Hence a $30 \mathrm{Kg}$ pilot plant medium frequency induction furnace was used to prepare SS304Mo and the developed austenite steel samples. The melting unit was lined properly and the iron molds (inner diameter $70 \mathrm{~mm}$ ) were utilized in the process of the melts casting. The samples of the hot forged steels were solution annealed at $1050 \mathrm{C}$ for $30 \mathrm{~min}$. followed by water quenching process.

The produced alloys compositions were specified using $\mathrm{x}$-ray fluorescence (XRF) and spectrographic analysis (SPGA). The obtained results are shown in Table (1). Determination of the total boron content in the produced stainless-steel alloys was undertaken using ICP-OES Optima 2000 DV Perkin Elmer.

Table (1) shows that there is a similarity concerning the chemical composition of SS304Mo and AISI304Mo stainless steels while the remaining three modified stainless-steel alloys are of base composition SS304Mo

Table (1): Chemical composition of the investigated stainless steel samples

\begin{tabular}{ccccccccccccccccc}
\hline \multirow{2}{*}{ Steel Code } & \multicolumn{11}{c}{ Chemical Composition, wt \% } \\
\cline { 2 - 6 } & $\mathrm{C}$ & $\mathrm{Si}$ & $\mathrm{Mn}$ & $\mathrm{P}$ & $\mathrm{S}$ & $\mathrm{Cr}$ & $\mathrm{Ni}$ & $\mathrm{Mo}$ & $\mathrm{W}$ & $\mathrm{Cu}$ & $\mathrm{Ti}$ & $\mathrm{V}$ & $\mathrm{Al}$ & $\mathrm{N}$ & $\mathrm{B}$ & $\mathrm{Fe}$ \\
\hline SS304Mo & 0.07 & 1.00 & 0.6 & 0.018 & 0.018 & 17.34 & 9.17 & 2.57 & 0.02 & 0.12 & 0.007 & 0.11 & 0.027 & 0.039 & 0.0035 & 68.68 \\
SS304MoTi & 0.07 & 0.66 & 0.99 & 0.018 & 0.024 & 17.39 & 8.47 & 2.35 & 0.02 & 0.12 & 0.236 & 0.11 & 0.04 & 0.0378 & 0.0025 & 69.24 \\
SS304MoB & 0.07 & 0.41 & 0.84 & 0.012 & 0.021 & 16.20 & 8.48 & 2.21 & 0.02 & 0.14 & 0.03 & 0.1 & 0.023 & 0.041 & 0.104 & 71.11 \\
SS304MoBTi & 0.07 & 0.77 & 0.87 & 0.017 & 0.021 & 17.2 & 8.35 & 2.32 & 0.03 & 0.13 & 0.382 & 0.12 & 0.042 & 0.0346 & 0.106 & 69.38 \\
\hline
\end{tabular}




\section{Experimental details}

Attenuation testing

The $\mathrm{BF}_{3}$ neutron detector and ${ }^{241} \mathrm{Am}-\mathrm{Be}$ neutron source with activity $100 \mathrm{mCi}$ and neutron yield = $(1.1-1.4)^{*} 10^{7} \mathrm{n} / \mathrm{s}$ were utilized in the present work. The former was used to detect the slow, total slow and neutrons with energy higher than $10 \mathrm{keV}$. Source to detector distance was kept constant at 7 $\mathrm{cm}$. Polyethylene material $(6 \mathrm{~cm}$ x $6 \mathrm{~cm})$ was used for slow neutrons while boron carbide sheets were used to obtain fast neutrons $\left(\mathrm{E}_{\mathrm{n}}\right.$ higher than 10 $\mathrm{keV})$. The neutrons macroscopic cross section $(\Sigma)$, can be calculated from the formula:

$$
\mathrm{I}=\mathrm{I}_{0} \mathrm{e}^{-\sum \mathrm{x}}
$$

Where, $\mathrm{I}_{0}$ : Intensity of neutrons without sample,

I: Intensity of neutrons with sample of thickness (x).

The gamma ray attenuation parameters of the produced stainless-steel samples were determined for several gamma transitions emitted from ${ }^{232} \mathrm{Th}$ source $(238.63,338.28,583.19,911.2$ and 2614.51 $\mathrm{keV})$. The measurements were performed using $\mathrm{NaI}$ (T1) detector.

A comparison between the experimental and the corresponding theoretical attenuation parameters was performed using WinXCom computer program (Version 3.1) [6] for several stainlesssteel samples having different iron concentrations.

\section{Corrosion resistance testing}

Cyclic anodic polarization technique was used to test the corrosion of the investigated steels. Steel samples were treated properly by polishing process to a 1200-grit finish, ultrasonically cleaning and rinsing with ethanol and finally dried. A single compartment-cylindrical glass cell having the known three-electrode unit with a $\mathrm{Pt}$ counter electrode was used. Analytical grade chemicals and bi-distilled water were used to prepare sodium chloride medium. The cyclic anodic polarization measurement was performed. The potential was recorded as a function of time till steady state potential values were reached. The potential measurements were carried out at room temperature using the electronic multi-meter (Type Escord EDM-2116). The corrosion rate/year was deduced for all the investigated samples.

\section{Metallography}

For metallurgic studies the samples were polished using various grades of SIC paper up to 1200 grit and hereafter by cloth using $1 \mu \mathrm{m}$ diamond paste then these polished samples were etched in an electro -oxalic acid (20\%) solution. An optical microscope was used to determine the microstructures of different areas of the investigated alloys.

\section{Mechanical testing}

The stainless-steel samples were exposed to Vickers hardness test after being prepared by grinding and polishing processes. Zwick-Roel hardness tester machine with $150 \mathrm{Kg}$ working load was used to undergo the hardness measurements. Round tensile specimens were machined with dimensions according to ASTM-E8 specification. Yield strength, ultimate tensile strength, elongation and reduction of area were measured for the investigated samples at room temperature using tensile machine (EZ20-20KN) with a cross head speed of $0.3 \mathrm{~mm}$. Impact testing machine (150J) with Computer Aided Measurement System (CAMS) with software capable of statistical analysis of data and quality control was used to prepare the Charpy V-noth specimens $(0.1 \mathrm{~cm} \mathrm{x}$ $0.1 \mathrm{~cm} \times 0.55 \mathrm{~cm})$. Impact test was carried out at $20^{\circ} \mathrm{C}$.

\section{Results and Discussion \\ Attenuation properties \\ Neutrons attenuation}

The attenuation properties of the present developed austenitic stainless-steel alloys for neutrons with energies higher than $10 \mathrm{keV}$, slow and total slow neutrons were determined from which the corresponding macroscopic neutron cross sections were evaluated and presented in Table (2).

Table (2) shows that there is an increase in the macroscopic cross sections for all modified austenitic stainless steels containing $\mathrm{B}$, $\mathrm{Ti}$ or $\mathrm{Ti}$ and B (SS304MoB and SS304MoTiB) as compared to the standard SS304Mo steel. Also, the sample containing $\mathrm{Ti}$ and $\mathrm{B}$ (SS304MoBTi) is found to have the highest macroscopic cross section for the slow and total slow neutrons whereas its value is lower than SS304MoB for the neutrons higher than $10 \mathrm{keV}$. These results confirm the fact that borated stainless steels fulfill the requirements of having a proper shielding material that achieve the necessary safety conditions [7].

The half value layer (HVL) [8] for the three investigated types of neutrons were calculated from the obtained data of the removal cross sections and the results are given in Fig. (1). 
Figure (1) reveals that the standard austenitic stainless steels (SS304Mo) and the SS304MoTi have nearly comparable higher HVL values as compared with the other SS304MoB and SS304MoTiB stainless steel samples. These observations were noticed for three types of the neutrons (slow, total slow and neutrons higher than $10 \mathrm{keV})$.

\section{Gamma rays attenuation}

The experimental mass attenuation coefficients $\left(\sigma_{\text {Exp }}\right)$ were evaluated making use of the linear shielding parameters that were experimentally obtained for different five gamma ray energies. Fig. (5) shows the dependence of the mass

Table (2): The neutron macroscopic cross sections for the studied alloys

\begin{tabular}{cccc}
\hline Sample Code & $\sum_{>10 K e v}\left(\mathbf{c m}^{-\mathbf{1}}\right)$ & $\sum_{\mathrm{t}}\left(\mathbf{c m}^{-\mathbf{1}}\right)$ & $\sum_{\mathrm{s}}\left(\mathbf{c m}^{-\mathbf{1}}\right)$ \\
\hline SS304Mo & $0.0282 \pm 0.0073$ & $0.0627 \pm 0.0067$ & $0.0402 \pm 0.0091$ \\
SS304MoTi & $0.0293 \pm 0.0101$ & $0.0629 \pm 0.0077$ & $0.0404 \pm 0.0082$ \\
SS304MoB & $0.0344 \pm 0.0083$ & $0.0735 \pm 0.0104$ & $0.0416 \pm 0.0063$ \\
SS304MoBTi & $0.0317 \pm 0.0114$ & $0.0741 \pm 0.0143$ & $0.0529 \pm 0.0186$ \\
\hline
\end{tabular}
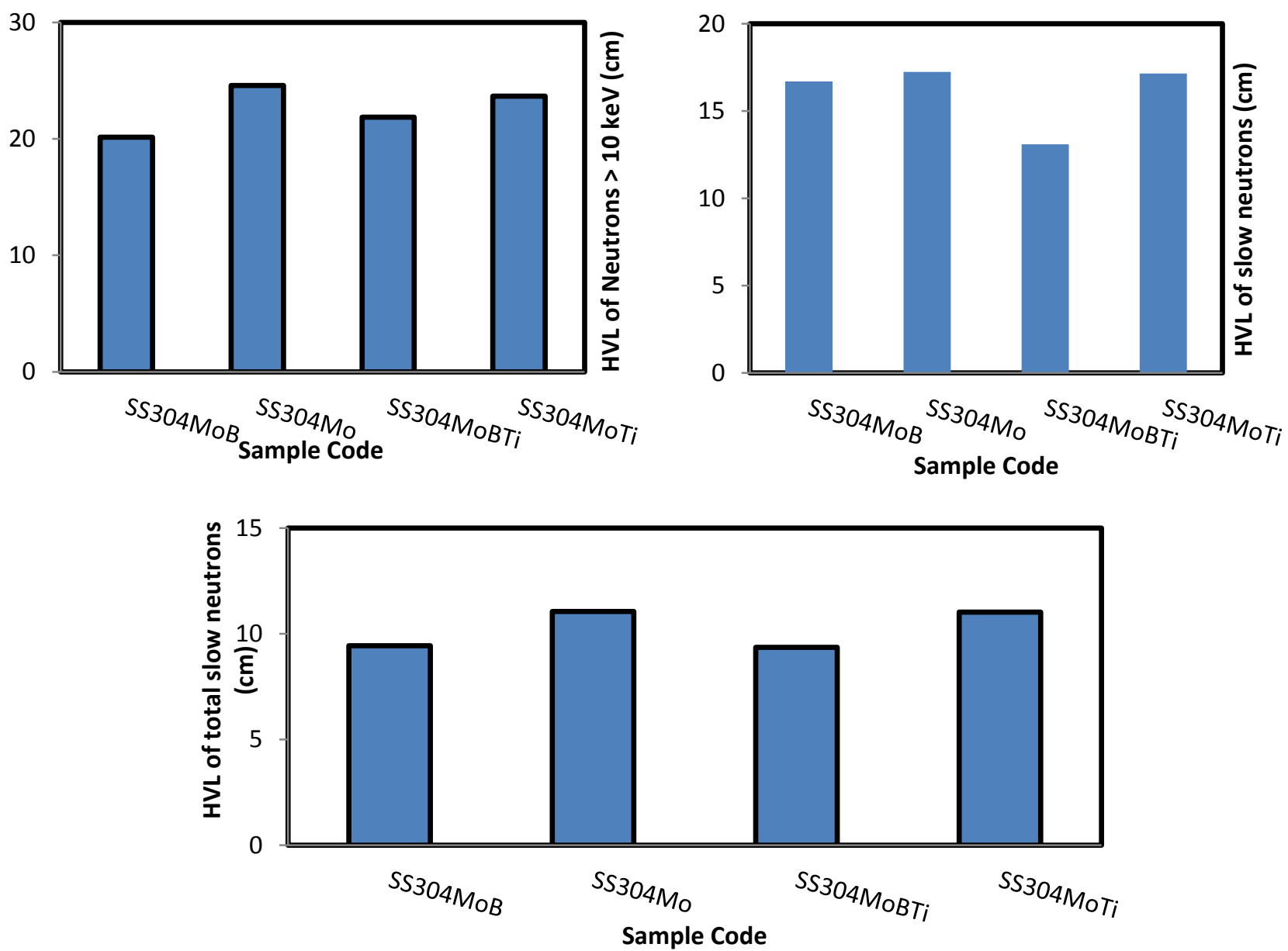

Fig. (1): Half value layer of the investigated stainless-steel alloys for neutrons 

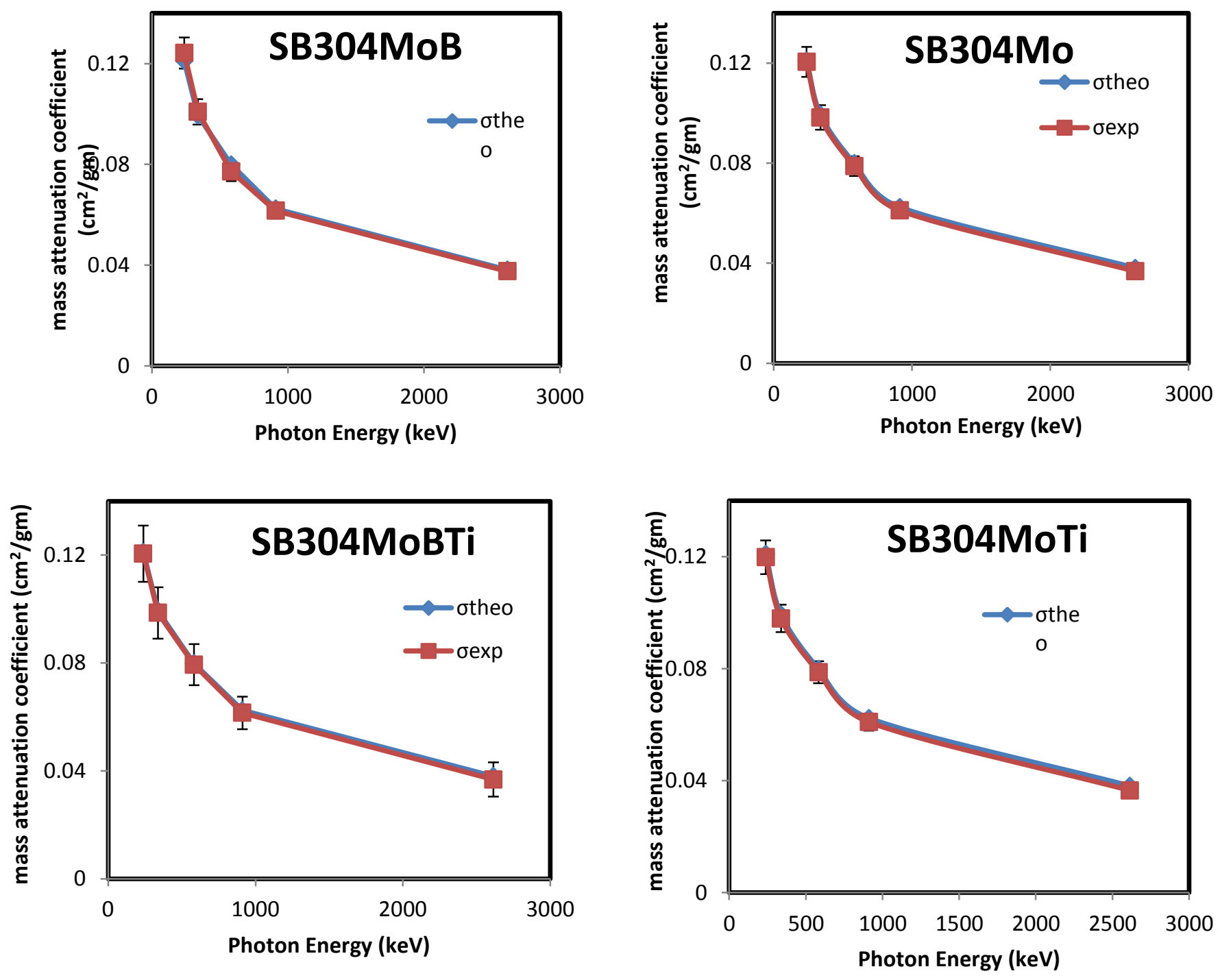

Fig. (2): Experimental and theoretical mass attenuation coefficients of the investigated alloys

\section{Corrosion rate}

The corrosion rates in $\mathrm{mm} / \mathrm{y}$ in $3.5 \mathrm{wt} \%$ of the investigated stainless steels alloys are shown in Table (3) and Fig. (3). The obtained results indicated that the borated stainless steel (SS304MoB) has corrosion rates lower than all the other samples while the investigated steels (SS304MoTi and SS304MoTiB) exhibit corrosion rates lower than the conventional SS304Mo steel samples. Therefore, the following arrangement simplifies the relevant magnitude of each corrosion rate in ascending order;

\section{SS304MoB $<$ SS304MoBTi $<$ SS304MoTi $<$} SS304Mo

The superiority of the borated stainless steels is based on the presence of the secondary phase. Attacking the grain boundaries may play an important role of that reduction [8].

\section{Microstructure}

The appearance of a very large number of twins in the optical micrographs of the investigated samples as shown in Fig. (4) illustrates the fully austenite phase of them. 
Table (3): Corrosion rate of the investigated steels in $3.5 \mathrm{wt} \% \mathrm{NaCl}$ solution

\begin{tabular}{c|c}
\hline Sample & Corrosion Rate $(\mathbf{m m} / \mathbf{y})$ \\
\hline SS304Mo & 0.0737 \\
SS304MoTi & 0.0318 \\
SS304MoB & 0.0217 \\
SS304MoBTi & 0.0229 \\
\hline
\end{tabular}

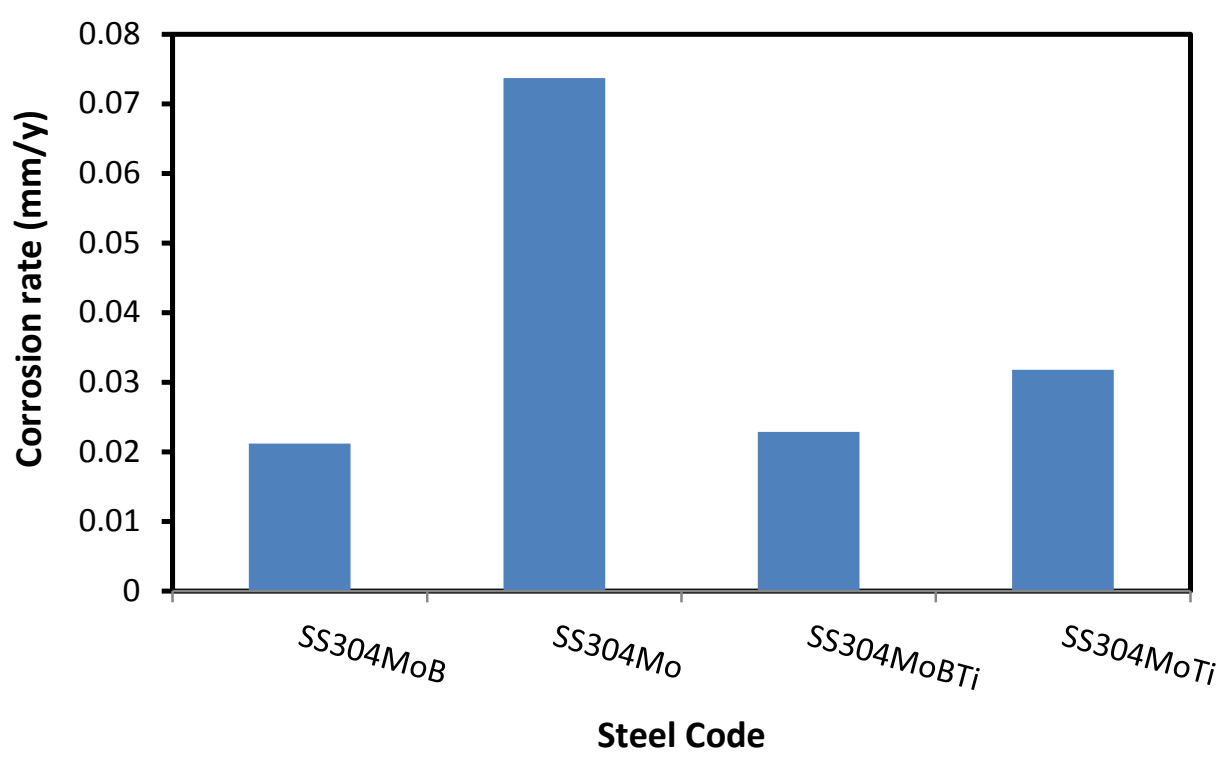

Fig. (3): Corrosion rate of the investigated steels in $3.5 \mathrm{wt} \% \mathrm{NaCl}$ solution
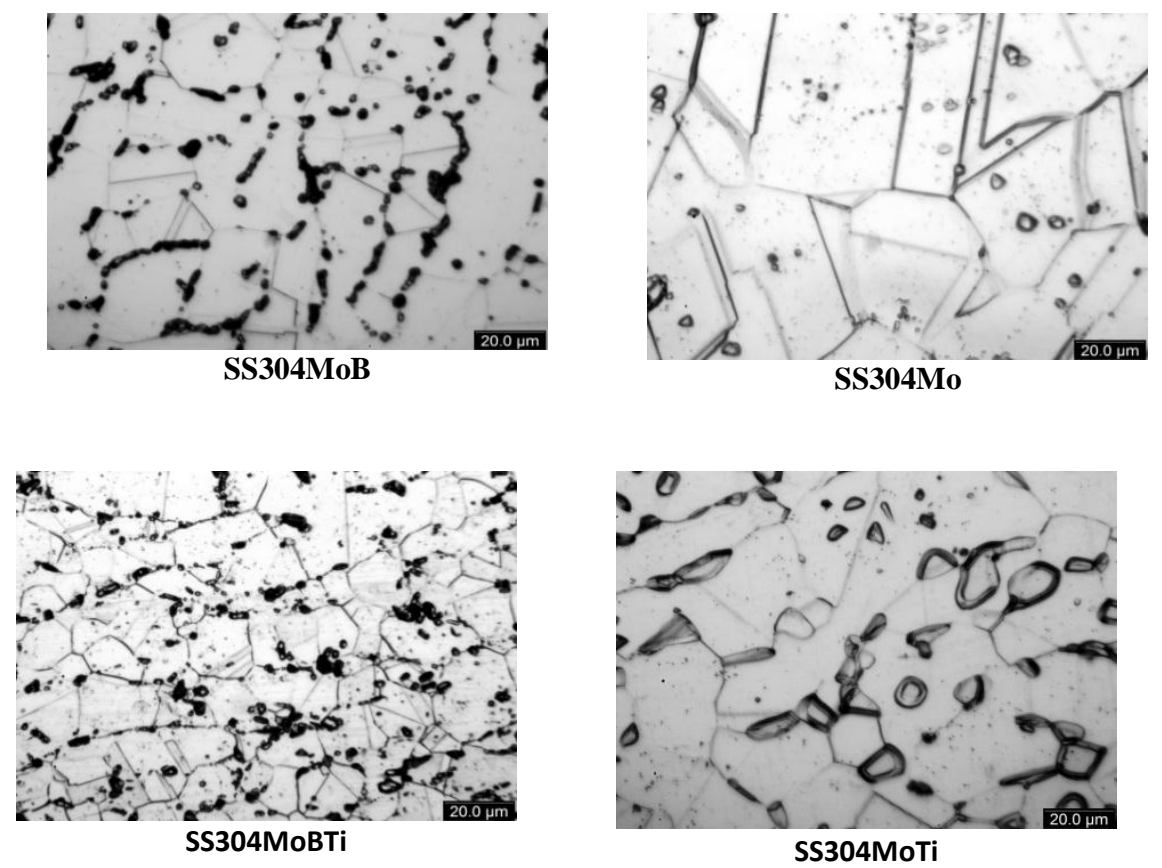

Fig. (4): Microstructure of the investigated stainless steel 
The structures were illustrated with an electrolytic etching. Usually, this test is intended in the solubilized austenitic SS304Mo to observe the step structure at the grain boundaries and in the sensitized austenitic SS304Mo to dissolve the chromium depleted areas around the carbides at the grain boundaries. In these figures, a large amount of particles can be illustrated on an austenitic matrix almost uniaxial. The particles have an extended form that follows the rolling direction.

It can be noted that the boron is found mostly in the particles. Also, twice as much $\mathrm{Cr}$ is found in the particles compared with $\mathrm{Fe}$. In the matrix, where there is barely any boron, the predominant element is $\mathrm{Fe}$, then $\mathrm{Cr}$ and $\mathrm{Ni}$. The proportion of $\mathrm{Cr}$ to $\mathrm{Fe}$ in the matrix is 1 to 4 . So, it can be illustrated that the particles are composed of $\mathrm{Cr}$, $\mathrm{Fe}$, and $\mathrm{B}$. No big difference can be noted between both states that were studied [9].

\section{Mechanical properties}

To evaluate the effect of boron and titanium contents on the produced stainless steels it is necessary to measure the mechanical properties such as Vickers hardness, yield strength, ultimate tensile strength, and elongation, reduction of area and impact energy. The obtained results are given in Table (4) and Fig. (5).

The obtained results clearly indicate that the investigated austenitic steels SS304MoB and SS304MoTiB show higher yield strength and ultimate tensile strength than the standard SS304Mo steel, while the impact energy, elongation, and reduction area have lower values than the standard SS304Mo. The investigated SS304MoB steel has slightly higher hardness compared with the standard SS304Mo steel.

The strengthening effect of $\mathrm{B}$ or $\mathrm{Ti}$ and $\mathrm{B}$ is to great extent the reason of the solution hardening and precipitation strengthening effects of these elements as these elements are strong carbide or nitride formers. The higher B content increases the formation speed of intermetallic compounds and lowers the ductility.
The better tensile and impact properties of our samples can be advantageously utilized in fillet welds and lap joints where the positioning of base plates is such that leakage of neutrons through weld metal does not happen [9].

\section{Conclusion}

Three developed steel alloys with SS304Mo base composition having either $\mathrm{Ti}$ or $\mathrm{B}$ or $\mathrm{Ti}$ and $\mathrm{B}$ (SS304MoTi, SS304MoB and SS304MoTiB) were produced, tested for their shielding, mechanical and structural properties in order to illustrate their capability to be used as proper nuclear materials in the nuclear reactor domain. The macroscopic cross sections of total slow, neutrons with energy higher than $10 \mathrm{keV}$ and slow neutrons for the developed boron-titanium stainless steel were experimentally determined. The obtained results of the gamma rays attenuation properties proved that there is no remarkable difference between them because they have nearby equal values for their densities. The effect of boron content on the corrosion rates is clearly evident as it enhances their values compared with the standard steel alloys because of the presence of a secondary phase. The developed steels revealed austenitic microstructure. The reason for the obvious strengthening in the produced alloys is mainly due to the solution hardening and precipitation strengthening effects of $\mathrm{B}$ and Ti elements as these elements are strong carbide or nitride formers. Increasing $B$ concentration gives rise to the formation of intermetallic compounds and lowers the ductility. Also, the high work hardening rate caused by the austenite steels containing $\mathrm{Ti}$ increases both the tensile ductility and impact toughness. In general, the obtained attenuation and mechanical results strongly give a further support to the B-Ti stainless steel alloys to be of real valuable importance in the nuclear engineering domain. 

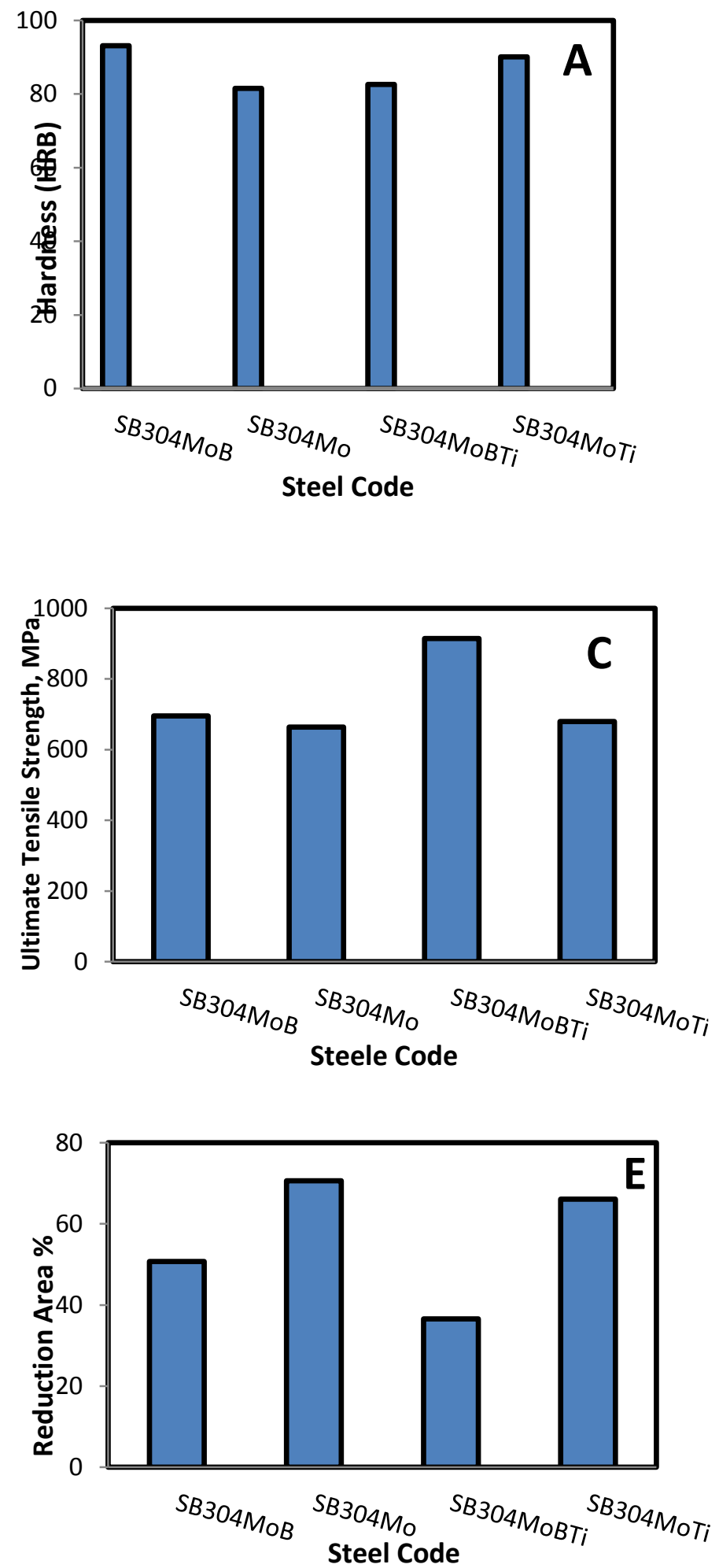
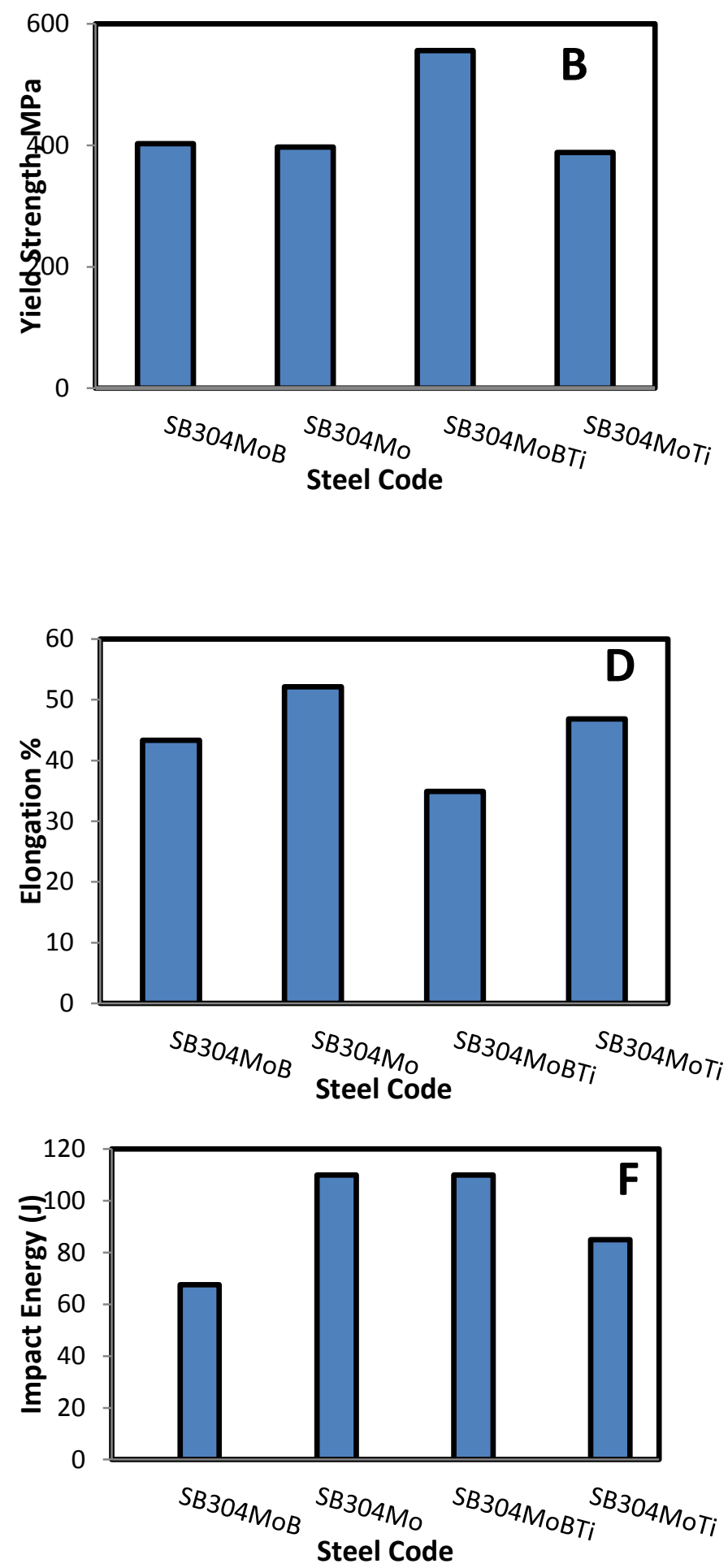

Fig. (5): Mechanical properties of the investigated stainless steel alloys; (A) Vickers hardness, (B) yield strength, (C) ultimate tensile strength, (D ) elongation, (E) reduction area, (F) impact energy 
Table (4): Mechanical properties of the investigated stainless-steel alloys; hardness, yield strength, ultimate tensile strength, elongation, reduction area and impact energy

\begin{tabular}{ccccccc}
\hline \multirow{2}{*}{ Sample Code } & \multicolumn{5}{c}{ Mechanical properties } \\
\cline { 2 - 7 } & $\begin{array}{c}\text { Hardness } \\
(\mathbf{H R B})\end{array}$ & $\begin{array}{c}\text { Yield } \\
\text { Strength } \\
\mathbf{M P a}\end{array}$ & $\begin{array}{c}\text { Ultimate Tensile } \\
\text { Strength, MPa }\end{array}$ & $\begin{array}{c}\text { Elongation } \\
(\boldsymbol{\%})\end{array}$ & $\begin{array}{c}\text { Red. Area } \\
(\boldsymbol{\%})\end{array}$ & $\begin{array}{c}\text { Impact } \\
\text { Energy } \\
(\mathbf{J})\end{array}$ \\
\hline SS304Mo & 81.5 & 397.147 & 664.2375 & 52.15465 & 70.6269 & 110 \\
SS304MoTi & 90.1 & 388.058 & 679.445 & 46.83695 & 66.112 & 85 \\
SS304MoB & 93.133 & 402.914 & 695.4725 & 43.2944 & 50.71605 & 67.5 \\
SS304MoBTi & 82.63 & 555.819 & 914.622 & 34.91705 & 36.6126 & 110 \\
\hline
\end{tabular}

\section{References}

1. L. Lherbier, solving nuclear storage issues, nuclear exchange, 34, 2012.

2. S. B. Robert, Borated stainless steels (ASTMA887-88) a comparison of grade AneutrosorbPlus and grade B- neutrosorb, application engineering, carpenter technology Corporation, 657, 1991.

3. P. Marmy, Titanium Alloys Irradiation Testing, Report on ITER TASK BL 14.2, 6, 2000.

4. V.F. David, C.E. John, L.W. Landa, B.R. Raul, General and localized corrosion of austenitic and borated stainless steels in simulated concentrated ground water, proc Americansociety of mechanical engineers pressure vessels and piping division (ASMEPVP) conference in San Diego, CA 25-29, 2004.

5. M.Victoria, N. Baluc, P. Spätig, Structural Material for Fusion Reactors. EPFL-CRPP Fusion Technology Materials, CH-5232 Villigen PSI, Switzerland, 2001.

6. L. Gerward, N.Guilbert, K.B. Jensen, H. Leving, 'WinXCom - A Program for
Calculating X-Ray Attenuation Coefficients. Radiation Physics and Chemistry, Vol. 71, PP. 653- 654, 2004.

7. M. Bastürk, J. Arztmann, W. Jerlich, N. Kardjilo, E. Lehman, M. Zawisky, Analysis ofneutron attenuation in boron-alloyed stainless steel with neutron radiography andJEN-3 gauge, Journal of Nuclear Materials 341, 189-200, 2005.

8. D.A. Moreno, B. Molina, C. Ranninger, F. Montero, J. Izquierdo, Microstructural Characterization and pitting corrosion behavior of UNS530466 borated stainless steel, Corrosion 60, 6-573, 2004.

9. G. RajaKumar, G. D. J. Ram, S. R. K. Rao, Microstructure and Mechanical properties of Borated Stainless Steel (304B) GTA and SMA welds, La Metallurgia Italiana - n. 47,5, 2015.

10. H. Hänninen, "Material Development in New Reactor Designs -Gen III andSCWR Concept", 20th International Conference on Structural Mechanics in ReactorTechnology (SMiRT), August 9 14, 2009, Dipoli Congress Centre, Espoo, Finland. 